\title{
ATIVIDADE DE PESCA AMADORA DESENVOLVIDA NA ÁREA DE PROTEÇÃO AMBIENTAL DE GUAPIMIRIM, BAÍA DE GUANABARA, RJ
}

\author{
Rafael de Almeida Tubino ${ }^{1}$ \\ Bernardo Roxo Couto ${ }^{2}$ \\ Cassiano Monteiro Neto ${ }^{3}$
}

\section{Resumo}

Apesar de ser uma atividade popular, existem poucas informações sobre a prática da pesca amadora no Brasil. A falta de informações sobre o número de praticantes e o volume de captura, principalmente em ambientes costeiros, representa uma lacuna fundamental a ser preenchida, especificamente, em áreas protegidas onde o conhecimento representa um ponto chave na condução de políticas de gestão ambiental. O objetivo do trabalho é caracterizar a atividade de pesca amadora desenvolvida no interior da Área de Proteção Ambiental de Guapimirim, localizada no fundo da Baia de Guanabara, caracterizando o perfil sociocultural do praticante, a composição específica das capturas, definindo as variações de tamanho das espécies capturadas. As informações foram obtidas através do acompanhamento direto dos pescadores em abordagens durante o momento da pescaria utilizando-se um protocolo de perguntas pré-estabelecido. Cada pescador entrevistado forneceu informações sobre o seu grau de experiência, motivação, custos e tempo gasto na atividade. Dos 49 entrevistados (idade média $=51,8$ anos), todos eram homens, sendo que $41 \%$ destes afirmaram ser possuidores de uma escolaridade ao nível do ensino médio; $79 \%$ tem uma frequência de pesca de 1 a 5 vezes por mês e experiência média de 14,3 anos de pesca em Guapimirim, sendo que $71 \%$ possuem embarcação própria e $83 \%$ sabem nadar. A despesa média por pescaria é de R\$ 100,20 e apenas $24 \%$ são afiliados a clubes de pesca; $8 \%$ participam de torneios e somente $65 \%$ dos pescadores possuem licença para pescar. Dos entrevistados, somente $54 \%$ conhecem a área de proteção ambiental, $10 \%$ conhecem a Estação Ecológica da Guanabara. Do total, $23 \%$ não conhecem as medidas mínimas de captura dos peixes pescados na região.

Palavras chave: APA Guapimirim; lazer; pesca amadora

\begin{abstract}
Even though it's a popular activity, there's few information about recreational fishery practice in Brazil. The lack of data about the number of fisherman and the captures volume in coast environment, is a fundamental gap to be filled. In conservation units, where the knowledge is key to environmental management policies, researches are even more important. The work aims to characterize the recreational fishery inside the Environmental Protection Area of Guapimirim, located in Guanabara Bay, characterizing the sociocultural profile of recreational fishers in the area and the captures specific composition, also defining the size range of captured species. The information was obtained through direct monitoring of fisherman in approaches during fishing, using a pre-established questionnaire. Each interviewed fisher provided information about his experience degree, costs and time spent on

\footnotetext{
${ }^{1}$ Curso de Ciências Biológicas, Universidade Gama Filho, RJ. E-mail: rattubino@ gmail.com

${ }^{2}$ Fundação Instituto de Pesca do Estado do Rio de Janeiro. E-mail: roxo.bio@ hotmail.com

${ }^{3}$ Laboratório de Biologia do Nécton e Ecologia Pesqueira/ECOPESCA, Departamento de Biologia Marinha, Universidade Federal Fluminense. E-mail: monteironeto@gmail.com
} 
the activity. In a total of 49 interviewed (age average $=51,8$ years), all men - with fishing experience average of 25,1 years, $71 \%$ fishes from 1 to 5 times/month and $76 \%$ own the boat. Spending an average of R $\$ 100,20 /$ fishery, 24\% joined fishing clubs, $8 \%$ compete on contests and only $65 \%$ have a fishing license. In the total, only $54 \%$ know the protection area, $10 \%$ know the Ecological Station of Guanabara and 23\% don't know the minimum capture size of fishes inside the area.

Keywords: APA Guapimirim; leisure; recreational fishing.

\section{Introdução}

A pesca consiste em uma atividade de retirada de recursos vivos de seu ambiente natural para consumo como alimento, venda ou simplesmente por esporte e lazer. As modalidades de pesca praticadas no Brasil podem ser classificadas como: esportiva/recreativa (amadora), de subsistência ou comercial (profissional) A pesca profissional é realizada por trabalhadores com registro junto ao Ministério do Trabalho, já a pesca amadora inclui o cidadão comum, que pratica esta atividade sem interesses comerciais. O Ministério da Pesca e Aquicultura divide a atividade de pesca amadora em três categorias distintas, a saber: a) embarcada, b) desembarcada e c) subaquática.

No Brasil, o setor da pesca amadora demonstrou nos últimos anos um crescimento considerável, com um grande número de novos praticantes a cada ano. Assim, o que anteriormente era somente uma atividade de lazer, ganhou novas perspectivas criando um grande mercado, movimentado por uma extensa cadeia produtiva que gera, anualmente, milhões de dólares em segmentos tão diversos como a importação e a exportação de materiais para a pesca, o turismo e a mídia especializada. Em 1997, este setor recebeu o apoio do Programa Nacional de Desenvolvimento da Pesca Amadora (PNDPA), criado pelo Ministério do Esporte e do Turismo/EMBRATUR e pelo Ministério do Meio Ambiente/IBAMA, com o objetivo de transformar a atividade em um instrumento de desenvolvimento econômico, social e de conservação ambiental. Atualmente, a pesca amadora, assim como todas as demais modalidades de pesca desenvolvidas no Brasil, estão sob a responsabilidade do Ministério de Pesca e Aquicultura. É uma atividade desenvolvida por pescadores de diferentes faixas etárias e níveis socioeconômicos, incluindo uma representativa parcela de populações que vivem em áreas costeiras metropolitanas. Colleman et al. (2004), estimaram que existem cerca de 50 milhões de pescadores amadores somente nos Estados Unidos, sustentando um segmento comercial especializado que movimenta anualmente cerca de US\$ 38,0 bilhões.

Apesar de ser uma atividade que possui muitos adeptos, existem poucas informações sobre sua prática no Brasil, especialmente em áreas protegidas. A falta de informações sobre o número de praticantes e o volume de pescado, representa uma lacuna fundamental a ser preenchida. Deve ser considerando que apesar de ser uma atividade de lazer, ela faz uso de recursos vivos, que por sua vez, devem ter os seus níveis populacionais compatíveis com a sustentabilidade dos estoques pesqueiros a que pertencem. Além disto, a pesca amadora é uma atividade comumente praticada em áreas urbanas, normalmente de multiuso, podendo gerar conflitos entre diferentes usuários. 
Diferentes autores têm chamado a atenção para os possíveis impactos provocados pela crescente atividade pesqueira amadora em diferentes partes do mundo (BUCHER, 2006). Há uma eminente preocupação com o aumento do número de praticantes e consequentemente, a elevação dos níveis de esforço de pesca, justamente sobre espécies que habitam áreas estuarinas e costeiras que não são exploradas pela pesca industrial (COLLEMAN et al., 2004).

Segundo Cooke e Cowx (2006), a noção de que a pesca amadora não contribui para o declínio dos estoques, deve ser avaliada com mais atenção. Coates (1995), estimou que anualmente são capturados em todo o mundo cerca de dois milhões de toneladas de peixes, somente pela pesca amadora.

No estado do Rio de Janeiro, a pesca amadora é uma prática de grande interesse por parte da população. Os praticantes encontram uma grande variedade de opções de ambientes costeiros para a sua prática como, por exemplo, praias arenosas expostas ou não, costões rochosos, além de ilhas oceânicas que oferecem uma opção da pesca embarcada. Esta variedade de ambientes e a facilidade de acesso aos locais de pesca representam elementos motivadores ao aumento do número de praticantes, sobretudo na região metropolitana.

Especificamente, a prática desta modalidade de pesca em áreas protegidas, representa um aspecto ainda mais relevante na condução de políticas de gestão ambiental, contudo ainda pouco investigado tecnicamente. Considerando que a prática de qualquer atividade que afete o equilíbrio das espécies em seu ambiente natural deve ser avaliada quanto aos seus impactos, é necessário que se conheça a sua estrutura e dinâmica, permitindo a elaboração de políticas específicas de ordenamento e gestão.

Desta forma, o problema central do presente trabalho recai sobre a possibilidade da pesca amadora praticada no interior de uma Unidade de Conservação (UC) costeira representar um fator de impacto para as populações de peixes que ocorrem neste sistema. Assim, questiona-se se a atividade de pesca amadora praticada na Área de Proteção Ambiental de Guapimirim é potencialmente impactante às populações de peixes da região.

O objetivo geral deste trabalho é caracterizar a atividade de pesca amadora praticada no interior da Área de Proteção Ambiental de Guapimirim. Os objetivos específicos são: a) caracterizar o perfil socioeconômico dos praticantes da pesca amadora no interior da APA de Guapimirim; b) definir o perfil motivacional dos praticantes; c) caracterizar a composição específica das capturas; d) definir as variações de tamanho das espécies capturadas e e) definir os padrões de esforço de pesca e produção.

\section{Material e métodos}

A Área de Proteção Ambiental de Guapimirim (APA de Guapimirim) é uma UC federal localizada no fundo da Baía de Guanabara, criada pelo em 25 de setembro de 1984, com o objetivo principal de proteger os remanescentes de manguezal situados no seu recôncavo e assegurar a permanência e sobrevivência de populações humanas que mantêm uma relação estreita com o ambiente. Possui uma área com cerca de 14.000 
hectares e abrange parte dos municípios de Magé, Guapimirim, Itaboraí e São Gonçalo (Figura 01).

No interior da APA, está localizada a Estação Ecológica da Guanabara (ESEC Guanabara) que foi criada em 15 de fevereiro de 2006. A ESEC Guanabara possui cerca de 2.000 ha e é uma UC de proteção integral, não sendo permitida a entrada de pessoas dentro dos seus limites, exceto para fins científicos ou educativos, com anuência de seu órgão gestor.

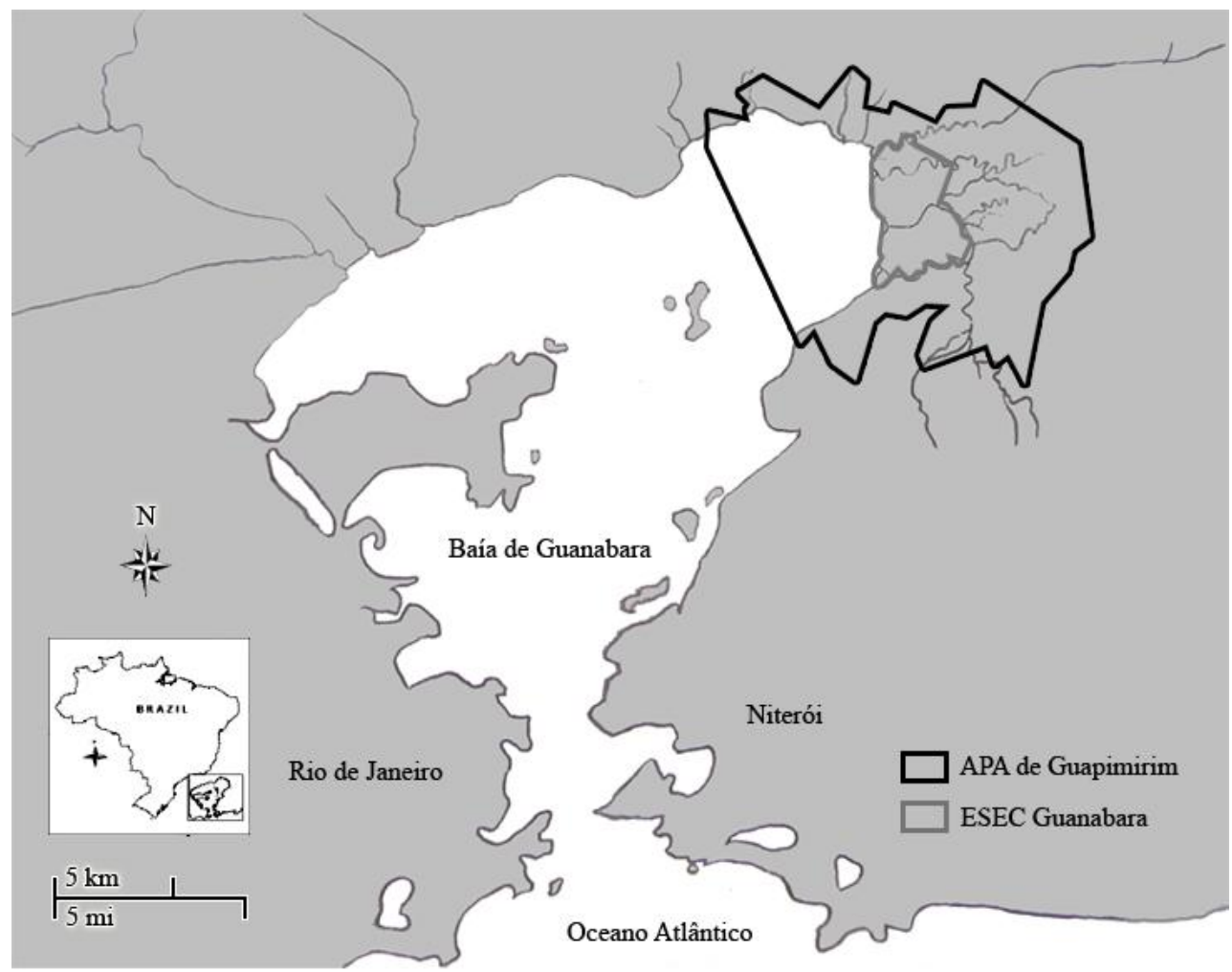

Figura 01. Mapa da Baía de Guanabara com a representação dos limites da Área de Proteção Ambiental de Guapimirim e da Estação Ecológica da Guanabara.

No período entre setembro de 2009 e setembro de 2011 foi estabelecido um programa amostral para coleta de informações sobre a atividade de pesca amadora desenvolvida no interior da APA de Guapimirim. Neste período, foram realizados acompanhamentos diretos das atividades dos pescadores através de abordagens durante o momento da pescaria. Os acompanhamentos foram realizados durante o período diurno, procurando-se respeitar, sempre que possível uma periodicidade mensal. Cada pescador foi entrevistado no sistema face a face, tomando como base um protocolo de perguntas pré-definido abordando aspectos relativos ao grau de experiência (tempo de pescaria), perfil socioeconômico dos praticantes, perfil motivacional e perfil da pescaria, incluindo aspectos referentes aos seus custos, tempo gasto na atividade e tipo de equipamento usado.

Com a permissão dos pescadores, os exemplares capturados foram biometrados (medidos em $\mathrm{cm}$ e pesados em $\mathrm{kg}$ ). Os pescadores entrevistados, de forma voluntária, 
assinaram um Termo de Consentimento Livre e Esclarecido com informações sobre o projeto de pesquisa, assegurando a integridade do voluntário, quanto ao uso de suas informações pessoais.

O questionário abordando o perfil motivacional dos praticantes foi elaborado com base na proposta de Schramm e Gerard (2004) com modificações, de forma que os pescadores entrevistados atribuíssem notas de um a cinco em graus de importância (1 Sem importância; 2 - Pouco importante; 3 - Moderadamente importante; 4 - Muito importante; e 5 - Extremamente importante) à 16 diferentes motivos que levam o praticante a escolher a pesca amadora como sua atividade recreacional, os motivos abordados foram: "para ganhar uma competição (troféu)", "fugir da exigência de outras pessoas", "para a recreação em família", "para alimentação", "para demonstrar minhas conquistas", "para desenvolver minhas habilidades (superação)", "para estar próximo aos amigos", "para ficar ao ar livre", "para reafirmar/lembrar uma ligação afetiva", "para relaxar", "para sair da rotina", "para testar meus equipamentos", "pela exigência da pesca", "pelo desafio do esporte", "pra manter-se próximo a água" e "soltar o peixe".

Os exemplares capturados pelos pescadores abordados foram identificados com base na literatura (FIGUEIREDO; MENESES, 2000; OYAKAWA et al. 2006). Com o objetivo de comparar os comprimentos médios das espécies registradas nas capturas acompanhadas, informações referentes a valores de comprimento médio de primeira maturação (Lt50) e comprimento máximo (Lmax) das espécies foram obtidas na literatura.

\section{Resultados}

Foram identificados cinco clubes de pescaria no interior da APA em funcionamento, sendo o mais antigo com 30 anos. A maior parte dos clubes oferece uma estrutura mínima para os praticantes, que inclui rampa ou cais, garagem para embarcações e banheiros. Uma contagem das embarcações permitiu uma estimativa de 143 barcos em possibilidade de uso. Na sua maioria, os clubes funcionam com o pagamento de mensalidades dos sócios que variam entre R \$ 80,00 e R \$100,00.

\section{a) Caracterização do perfil social do praticante}

No período amostral, efetuou-se um total de 56 entrevistas com 49 pescadores diferentes em onze dias de acompanhamento. Todos os pescadores entrevistados estavam em embarcações com motor de popa. Na sua maioria, utilizavam como petrecho de pesca, um ou dois caniços de fibra de vidro ou carbono, com molinete e um único anzol por linha. $\mathrm{O}$ conjunto de pescadores entrevistado foi composto apenas por praticantes do sexo masculino, com idade média de 51,8 anos, variando entre 15 e 78 anos. A maioria dos entrevistados $(36,0 \%)$ se enquadrou entre 50 e 59 anos de idade.

O tempo médio de experiência de pesca registrado para os praticantes foi de 25,4 anos e o tempo médio de experiência de pesca na região da APA de Guapimirim foi de 14,3 anos. A maior parte dos entrevistados afirmou saber nadar (83,0\%) e possuir embarcação própria (71,0\%), pescando costumeiramente acompanhado (74,0\%). A 
maioria dos pescadores $(76,0 \%)$ não afirmou ser filiado a nenhum clube ou associação de pesca e 92,0\% afirmaram não participar de torneios de pesca. Dos praticantes entrevistados, $41,0 \%$ possuem diploma de conclusão do ensino médio.

A frequência média mensal de pescarias do conjunto de praticantes foi de 4,2 $( \pm 5,0)$ vezes e a maioria dos pescadores. O custo médio das pescarias foi de $\mathrm{R} \$ 100,20$ $( \pm 8,3)$, contemplando gastos com isca $(50,0 \%)$, combustível para a embarcação $(25,0 \%)$ e alimentação $(25,0 \%)$.

Do total de praticantes entrevistados, $14,3 \%$ se enquadravam na condição legal de isenção da licença de pesca amadora e $85,7 \%$ na condição de obrigatoriedade. Contudo, desta parcela, apenas $51,0 \%$ afirmaram possuí-la. Cerca da metade dos praticantes abordados (54,0\%), afirmaram conhecer a APA de Guapimirim e somente 10,0\% conhecem a Estação Ecológica da Guanabara. Com relação à medida mínima de captura, a maioria dos entrevistados $(77,0 \%)$ afirmou conhecê-las, contudo, apenas 33,0\% indicaram possuir medida na embarcação.

\section{b) Caracterização do perfil motivacional do pescador}

O perfil motivacional dos pescadores indicou que as três principais motivações apontadas são: "para relaxar", "para estar próximo aos amigos" e "para sair da rotina" (Figura 02).

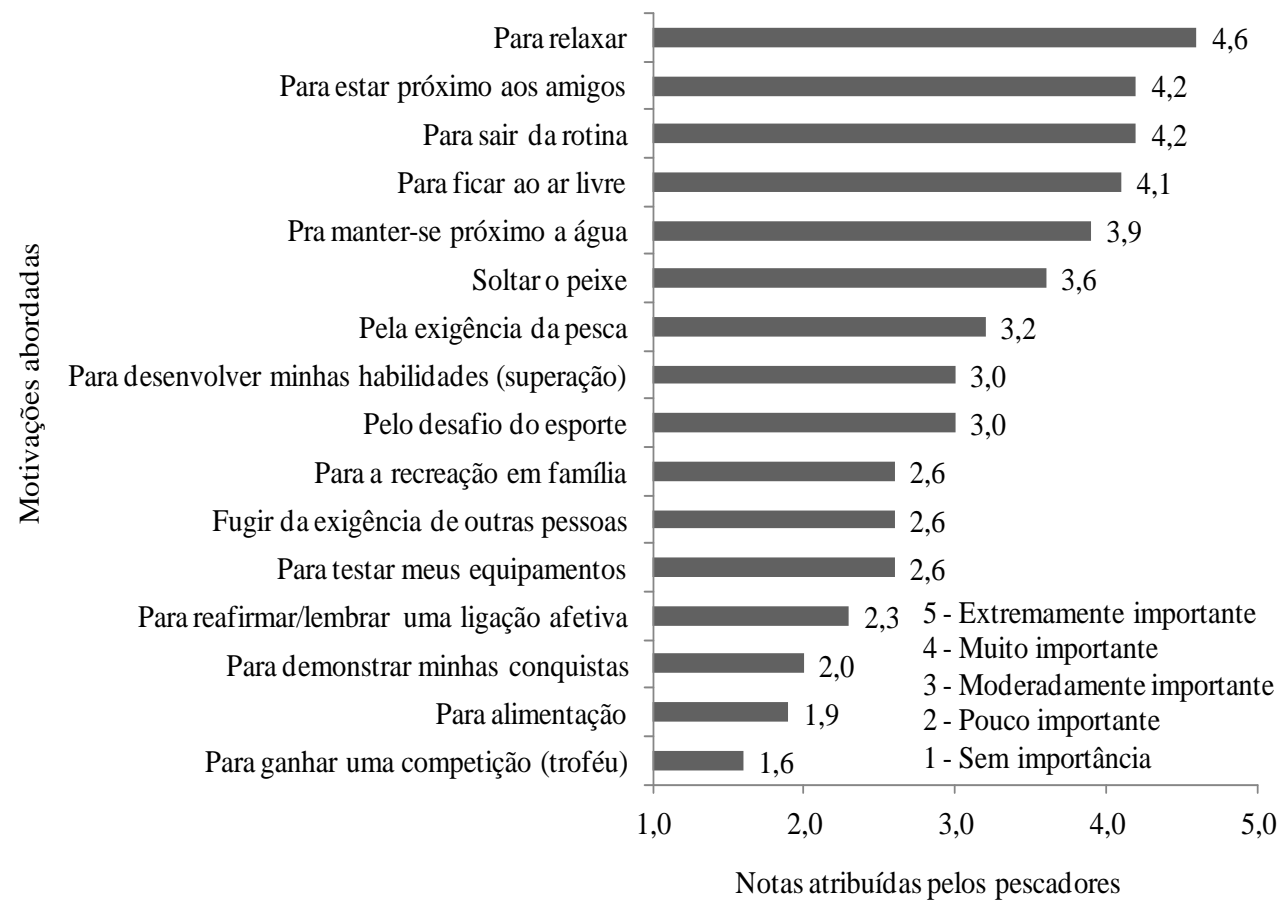

Figura 02. Valores médios relativos aos fatores motivacionais apresentados aos praticantes de pesca amadora na APA de Guapimirim.

\section{c) Composição faunística das capturas, produção e produtividade pesqueira}

De um total de 252 exemplares capturados, foram registradas dez espécies de peixes pertencentes a oito famílias diferentes. A composição das capturas foi representada 
principalmente pelas espécies do gênero Centropomus, são elas o robalo-peba $(C$. parallelus) com registro de 137 exemplares capturados e robalo-flecha (C. undecimalis) com registro de 54 exemplares (Tabela I).

A espécie mais abundante nas capturas foi $C$. parallelus $(54,5 \%)$ que também foi registrada como a de maior frequência de ocorrência (62,8\%), seguida por C. undecimalis, com abundância relativa de $21,3 \%$ e frequência de ocorrência de $37,2 \%$ e Genidens genidens com abundância relativa de $8,7 \%$ e frequência de ocorrência de $20,9 \%$. As demais espécies não apresentaram valores de abundância relativa superiores a 5,0\% e frequências de ocorrência superiores a 10,0\%. As principais espécies descartadas são $G$. genidens com 54,5\% e C. parallelus com 54,3\% (Tabela II). Entre as dez espécies registradas nas capturas, três são exclusivamente de ambientes dulcícolas, são elas $H$. malabaricus, $R$. quelen e $C$. gariepinus. Apesar de não ter sido registrada nenhuma espécie endêmica, verificou-se a presença de uma espécie exótica, o bagre-africano $(C$. gariepinus).

Tabela I - Lista de espécies capturadas pela pesca amadora na APA de Guapimirim, nome popular, família e número de indivíduos registrados.

\begin{tabular}{|c|c|c|c|}
\hline Espécie & Nome popular & Família & $\begin{array}{c}\text { Número } \\
\text { de } \\
\text { indivíduos }\end{array}$ \\
\hline Centropomus parallelus Poey, 1860 & Robalo-peba & Centropomidae & 137 \\
\hline Centropomus undecimalis (Bloch, 1792) & Robalo-flecha & Centropomidae & 54 \\
\hline Genidens genidens (Cuvier, 1839) & Bagre-guri & Ariidae & 22 \\
\hline Genidens barbus (Lacépède, 1803) & Bagre-papai & Ariidae & 9 \\
\hline Micropogonias furnieri (Desmarest, 1823) & Corvina & Sciaenidae & 11 \\
\hline Clarias gariepinus (Burchell, 1822) & Bagre-africano & Clariidae & 7 \\
\hline Elops saurus Linnaeus, 1766 & Ubarana & Elopidae & 6 \\
\hline Rhamdia quelen (Quoy \& Gaimard, 1824) & Jundiá & Heptapteridae & 3 \\
\hline Hoplias malabaricus (Bloch, 1794) & Traíra & Erythrinidae & 2 \\
\hline Mugil liza Valenciennes, 1836 & Tainha & Mugilidae & 1 \\
\hline \multicolumn{3}{|c|}{ 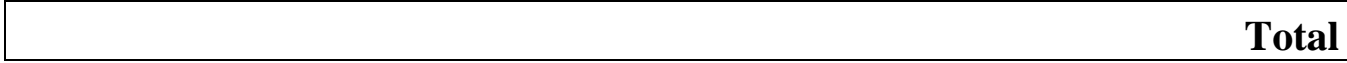 } & 253 \\
\hline
\end{tabular}

Em relação ao status de conservação das espécies, apenas três apresentaram grau de avaliação de acordo com a lista vermelha da União Internacional para a Conservação da Natureza e dos Recursos Naturais das Espécies Ameaçadas (IUCN) (Tabela II). Destas, as espécies G. genidens e E. affinis foram classificadas como pouco preocupantes e a corvina foi a única classificadas como ameaçada. 
Tabela II - Lista de espécies registradas nas capturas de pesca amadora na APA de Guapimirm

\begin{tabular}{|c|c|c|c|c|c|}
\hline Espécie & $\begin{array}{l}\text { AR } \\
(\%)\end{array}$ & $\begin{array}{l}\text { FO } \\
(\%)\end{array}$ & $\begin{array}{l}\text { FD } \\
(\%)\end{array}$ & $\begin{array}{l}\text { Comprimento } \\
\text { médio (DP) }\end{array}$ & $\begin{array}{c}\text { Estado de } \\
\text { conservação } \\
\text { (IUCN) }\end{array}$ \\
\hline C. parallelus & 54,5 & 62,8 & 54,3 & $26,4(3,6)$ & Não avaliada \\
\hline C. undecimalis & 21,3 & 37,2 & 16,7 & $36,3(7,5)$ & Não avaliada \\
\hline G. genidens & 8,7 & 20,9 & 54,5 & $22,3(3,0)$ & Pouco preocupante \\
\hline G. barbus & 3,6 & 9,3 & 44,4 & $32,9(12,9)$ & Não avaliada \\
\hline M. furnieri & 4,3 & 7,0 & 0,0 & $26,5(4,7)$ & Ameaçada \\
\hline C. gariepinus & 2,8 & 4,7 & 0,0 & $64,1(16,5)$ & Não avaliada \\
\hline E. saurus & 2,4 & 2,3 & 0,0 & $26,5(6,4)$ & Pouco preocupante \\
\hline R. quelen & 1,2 & 2,3 & 0,0 & $26,3(7,8)$ & Não avaliada \\
\hline H. malabaricus & 0,8 & 4,7 & 0,0 & $32,5(16,6)$ & Não avaliada \\
\hline M. liza & 0,4 & 2,3 & 0,0 & $40,0(0,0)$ & Não avaliada \\
\hline Total & 100,0 & & & & \\
\hline \multicolumn{3}{|r|}{ Média } & 17,0 & & \\
\hline
\end{tabular}

Legenda: Abundância relativa (AR); Frequência de ocorrência (FO); Frequência de descarte (FD); Comprimento médio com seu desvio padrão (DP).

Quando comparados os valores de frequência de ocorrência por classes de comprimentos registradas para os indivíduos capturados das diferentes espécies em relação ao comprimento médio de primeira maturação $\left(\mathrm{Lt}_{50}\right)$ obtido na literatura, verificamos que apenas as espécies de robalo-flecha e bagre-guri apresentam porcentagens abaixo de $50,0 \%$. Observa-se ainda que $24,1 \%$ dos indivíduos de robalo-flecha capturados apresentaram comprimentos superiores ao $\mathrm{Lt}_{50}$ (Tabela III).

Tabela III - Lista de espécies capturadas nas pescarias amadores praticadas na APA de Guapimirim.

\begin{tabular}{|l|c|c|l|c|}
\hline \multicolumn{1}{|c|}{ Espécies } & $\begin{array}{c}\text { Comp. médio } \\
\text { Guapimirim } \\
(\mathbf{c m})\end{array}$ & $\begin{array}{c}\text { Comprimento } \\
{\text { de } \mathbf{1}^{\mathbf{a}} \text { matur. }}^{\left(\mathbf{L t}_{\mathbf{5 0}}\right)}\end{array}$ & \multicolumn{1}{|c|}{ Referência } & $\begin{array}{c}\text { \% de } \\
\text { indivíduos } \\
\text { acima do }_{\text {Lt }}\end{array}$ \\
\hline C. parallelus & 26,4 & 26,0 & RODRIGUES (2005) & 88,9 \\
\hline C. undecimalis & 36,3 & 30,0 & GARCIA-CAGIDE (1994) & 24,1 \\
\hline G. genidens & 32,9 & 41,5 & REIS (1986) & 44,4 \\
\hline G. barbus & 22,3 & 8,5 & MAZZONI (2000) & 100,0 \\
\hline M. furnieri & 64,1 & 35,0 & BAIJOT (1997) & 100,0 \\
\hline C. gariepinus & 26,3 & 13,4 & GOMIERO (2007) & 100,0 \\
\hline E. saurus & 26,5 & - & - & - \\
\hline R. quelen & 32,5 & 16,7 & BARBIERI (1989) & 100,0 \\
\hline H. malabaricus & 26,5 & 24,3 & CARNEIRO (2005) & 72,7 \\
\hline M. liza & 40,0 & 40,0 & GARCIA-CAGIDE (1994) & 100,0 \\
\hline
\end{tabular}


Em relação à produção pesqueira, a pesca amadora desenvolvida na APA de Guapimirim contou com um esforço total de 134,67 horas (média de 3,2 horas). A produção total registrada foi de $145 \mathrm{~kg}$, resultando em uma produtividade pesqueira de 1,0 $\mathrm{kg} /$ pescador. A captura por unidade de esforço (CPUE) foi de $0,43 \mathrm{Kg} / \mathrm{h}$.

\section{Discussão}

$\mathrm{Na}$ APA de Guapimirim, todos os pescadores entrevistados pertenciam ao sexo masculino, assim como o observado por Basaglia e Vieira (2005) na praia do Cassino em Rio Grande, e por Peixer e Petrere (2009) no Rio Mogi-Guaçú, em Cachoeira das Emas, São Paulo. Se comparados ainda com Colella et al. (2011), em pesquisa realizada na Itália, onde a maioria era ainda de praticantes do sexo masculino, sugere ainda que este é um padrão mundial da atividade.

Registrou-se na APA de Guapimirim, uma amplitude de idade de 15 a 78 anos, muito próxima ao registrado por Basaglia e Vieira (2005) na praia do Cassino e por Peixer e Petrere (2009) no Rio Mogi-Guaçú, (SP), assim, esta é uma atividade bastante diversificada em relação à idade dos praticantes, indicando uma participação de indivíduos de diferentes faixas etárias.

Este trabalho, bem como o realizado por Peixer e Petrere (2009), foi desenvolvido no interior de ambientes dulcícolas ou estuarinos, abordando praticantes embarcados, deste modo os registros sugerem uma procura para a prática de pesca amadora nestes ambientes e nestas condições, de praticantes de maior idade e experiência, representando um panorama de pescadores que já praticam, em sua maioria, esta atividade há certo tempo e assim não sendo pescadores inexperientes.

Os dados registrados a respeito da assiduidade dos pescadores na região, assim como os registrados por Basaglia e Vieira (2005), sugerem uma associação desta atividade a finais de semana e feriados.

Para os praticantes desta atividade no interior da APA de Guapimirim, dos pescadores amadores que deveriam possuir a carteira que o licenciaria para a prática desta atividade, apenas a metade afirmou possuí-la, se comparado com o encontrado por Schork, Mottola e Silva (2010) em pescarias embarcadas em Santa Catarina, onde apenas um quarto dos praticantes possuía licença, a atividade no interior da APA de Guapimirim possui um grande número de pescadores licenciados, contudo, estes dados podem sugerir uma avaliação errada, já que a licença é de caráter obrigatório a todos os praticantes maiores de 18 anos de idade e menores de 65. Assim, o licenciamento para a prática da atividade encontra-se, ainda, longe do ideal em UCs.

Quanto ao perfil motivacional, os resultados mostram que os principais motivos apontados pelos praticantes encontram-se bem próximos aos observados por Schramm e Gerard (2004) nos EUA. Estes dados aliados ao fato de que grande maioria não é associada a nenhum clube de pesca e quase a totalidade dos entrevistados não participarem de torneios, indicam que a atividade realizada no interior da APA de Guapimirim, tem a clara finalidade de lazer. Esta constatação pode ser observada ainda na 
praia do Cassino/RS (BASAGLIA; VIEIRA, 2005), onde foi feita uma avaliação sobre os motivos que levariam os pescadores a considerarem a atividade como satisfatória.

Do total de indivíduos registrados nas capturas, 76,4\% pertenciam às espécies de robalo (Centropomus sp.) sugerindo que a pesca seletividade e preferência dos praticantes no interior da APA de Guapimirim. Duas espécies apresentaram mais da metade de seus indivíduos capturados descartados, o robalo-peba e o bagre guri, contudo estes dados devem ser avaliados com cautela já que o que pode parecer um grande valor na verdade não representa o que determina a legislação vigente. Isto acontece para o robalo-peba, já que aproximadamente $80 \%$ dos indivíduos capturados se enquadravam em condições de descarte segundo a legislação e com isso $30 \%$ dos indivíduos foram indevidamente mantidos pelos praticantes. Fator preocupante, já que estes que deveriam ser descartados também estavam abaixo do comprimento médio de primeira maturação $\left(\mathrm{Lt}_{50}\right)$, o que pode vir a afetar as populações da espécie viventes na região.

\section{Conclusões}

Os dados obtidos e as análises realizadas neste trabalho permitem as seguintes conclusões:

a) A atividade de pesca amadora praticada na Área de Proteção Ambiental de Guapimirim é potencialmente impactante às populações nativas de algumas espécies de peixes da região. São elas Centropomus undecimalis, C. parallelus, Genidens barbus e Micropogonias furnieri, uma vez que para as três primeiras espécies foram registradas altas taxas de captura de indivíduos abaixo do comprimento mínimo permitido para a captura e/ou abaixo do comprimento médio de primeira maturação sexual. Apesar da baixa frequência de ocorrência nas capturas, a espécie $M$. furnieri, deve ser observada com atenção já que possui status de conservação avaliado como ameaçada.

b) A maior parte dos praticantes da pesca amadora no interior da APA de Guapimirim não reconhece plenamente as UCs em que desenvolvem suas atividades, em especial, a Estação Ecológica da Guanabara (de uso restrito) e seus limites. Além disto, a maior parte dos pescadores amadores mostra um desconhecimento da legislação vigente acerca da obrigatoriedade do porte de registro de pescador e das medidas mínimas de captura das espécies.

c) O perfil motivacional proveniente do conjunto de praticantes traduz claramente um padrão fortemente relacionado à prática por lazer e em segundo plano, para o consumo. Conclui-se ainda, que o padrão apresentado pelos praticantes não segue a prática do "pesque e solte" no seu stricto sensu.

d) As principais espécies de interesse dos pescadores amadores na APA de Guapimirim, são os robalos, pertencentes a família Centropomidae. Os padrões observados para os descartes nas capturas são relacionados ao interesse do pescador pela espécie e ao tamanho dos indivíduos. Parte dos indivíduos capturados, especialmente de $C$. parallelus, $C$. undecimalis e $G$. barbus, 
encontram-se abaixo dos limites mínimos de captura e de primeira maturação sexual. Para as demais espécies, excetuando-se $M$. furnieri que possui status de conservação ameaçado, os dados não se traduzem em maiores preocupações, seja pela baixa ocorrência das espécies ou pelas capturas terem registrado indivíduos sempre acima dos limites de captura e de primeira maturação.

e) Os comprimentos médios das capturas na APA de Guapimirim, das espécies de robalo não atingiram a metade dos comprimentos máximos estimado pelos pescadores para cada uma delas, valor ainda menor se comparado com os comprimentos máximos encontrados na literatura. Os valores obtidos durante as amostragens refletiram em uma baixa produção de pescado e uma produtividade.

Este panorama geral da atividade mostra uma necessidade maior aproximação dos gestores das UCs com os praticantes, estabelecendo canais de divulgação de informações pertinentes a atividade (legislação e biologia das espécies), bem como a formação de um vínculo colaborativo de troca de informações que permitam os praticantes se tornem agentes de monitoramento das condições ambientais e das populações locais de peixes.

\section{Agradecimentos}

Aos gestores da APA de Guapimirim e da ESEC Guanabara (ICMBio) pelo apoio ao desenvolvimento do projeto. À SOS Mata Atlântica, pelo total apoio financeiro à pesquisa. Ao Programa de Iniciação Científica da Universidade Gama Filho pela concessão da bolsa para o aluno Bernardo Roxo Couto. Ao amigo Russo na condução no interior da APA.

\section{Referências bibliográficas}

BAIJOT, E.; MOREAU, J.; BOUDA, S. Hydrobiological aspects of fisheries in small reservoirs in the Sahel region. Technical Center for Agricultural and Rural Cooperation ACP-EU, Wageningen, Netherlands, 1997.

BARBIERI, G. Dinâmica da reprodução e crescimento de Hoplias malabaricus (Bloch, 1794) (Osteichthyes, Erythrinidae) da Represa do Monjolinho, São Carlos/SP. Rev. Bras. Zool. , v.6, p.. 225-233, 1989.

BASAGLIA, T.P.; VIEIRA, J.P. A pesca amadora recreativa de caniço na praia do cassino. RS: Necessidade de informações ecológicas aliada à espécie algo. Braz. J. Aquat. Sci. Technol., v. 9, n. 1, p. 25-29, 2005.

BUCHER, D.J. Spatial and Temporal Patterns of Recreational Angling Effort in a WarmTemperate Australian Estuary. Geographycal Research, v. 44, p. 87-94, 2006.

COATES, D. Inland capture fisheries and enhacement: status, constraints and prospects for food security. In: INTERNATIONAL CONFERENCE OF SUSTAINNABLE CONTRIBUTION OF FISHERIES TO FOOD SECURITY, 1995, Kyoto, Anais... FAO Kyoto; Rome, dez. 1995.

COLELLA, S. et al. Monitoring of recreational fisheries in italian seas: biological and social aspects. In: WORLD RECREATIONAL FISHING CONFERENCE, 6., 2011, Berlim, 2011, p. 63. 
COLEMAN, F.C. et al. The Impact of United States Recreational Fisheries on Marine Fish Populations. Science Magazine, v. 305, p. 1958, 2004.

CONDINI, M. V.; GARCIA, A. M.; VIEIRA, J. P. Descrição da pesca e perfil sócioeconômico do pescador da garoupa verdadeira Epinephelus marginatus (Lowe) (Serranidae: Epinephelinae) no Molhe Oeste da Barra de Rio Grande, Rio Grande do Sul, Brasil. PanAmerican Journal of Aquatic Sciences, v. 2, n. 3, p. 279-287, 2007.

COOKE, S. J.; COWX, I. G. Constrasting Recreational and Commercial Fishing: Searching for Common Issues to Promote Unified Conservation of Fisheries Resources and Aquatic Environments. Biological Conservation, v. 128, p. 93-108, 2006.

FIGUEIREDO, J. L.; MENESES, N. A. Manual de peixes marinhos do sudeste do Brasil. VI. Teleostei (5). Museu de Zoologia. São Paulo: Universidade de São Paulo, 2000.

FROESE, R.; PAULY, D. FishBase. World Wide Web electronic publication. Disponível em: $<$ www.fishbase.org, $>$. Acesso em: ago, 2011.

GOMIERO, L. M.; SOUZA, U. P.; BRAGA, F. M. S. Reprodução e alimentação de Rhamdia quelen (Quoy \& Gaimard, 1824) em rios do Núcleo Santa Virgínia, Parque Estadual da Serra do Mar, São Paulo, SP. Biota Neotropica, v. 7, 2007.

IUCN. Red List of Threatened Species International Union for Conservation of Nature and Natural Resources. Disponível em: < http://www.iucnredlist.org.> Acesso em: 12 nov. 2011.

MAZZONI, R.; PETITO, J.; MIRANDA, J. C. Reproductive biology of Genidens genidens, a catfish from the Maricá Lagoon, RJ. Ciência e Cultura, Rio de Janeiro, 2000.

OYAKAWA, O.T. et al. Peixes de riachos da Mata Atlântica. São Paulo: Editora Neotrópica, 2006.

PEIXER, J.; PETRERE JUNIOR, M., Sport fishing in Cachoeira de Emas in Mogi-Guaçu River, State of São Paulo, Brazil. Brazil J. Biol., v. 69, n. 4, p. 1081-1090, 2009.

REIS, E.G. Reproduction and feeding habits of the marine catfish Netuma barba (Siluriformes, Ariidae) in the estuary of Lagoa dos Patos, Brazil. Atlantica. 1986.

SCHORK, G; MOTTOLA, L. S. M.; SILVA, M. H. Diagnóstico da pesca amadora desembarcada na região de São Francisco do Sul (SC). Revista CEPSUL. Biodiversidade e Conservação Marinha, v. 1, n. 1, p. 8-17, 2010.

SCHRAMM JUNIOR, H. L.; GERARD, P. D. Temporal changes in fishing motivation among fishing club anglers in the United States. Fisheries Management and Ecology, v. 11, p. 313-321, 2004. 